\title{
Multiplication of seed potatoes by tuber formation in leaf axils of stems derived from single-bud stem cuttings
}

\author{
J. Marinus \\ Centre for Agrobiological Research (CABO), P.O. Box 14, 6700 AA Wageningen, \\ Netherlands
}

Received 23 May 1986; accepted 1 December 1986

Key words: potato, stem cutting, aboveground tubers, daylength, Solanum tuberosum

\section{Summary}

In the Netherlands there is need for a method of rapid multiplication of healthy basic seed potatoes of non-protected cultivars. Because in the past only relatively few underground tubers were harvested from stem cuttings, the formation of tubers in leaf axils was studied. Single-node cuttings were taken and planted in such a way that the buds were some centimetres above the soil surface.

An experiment was carried out with three cultivars. Some of the plants were grown under long-day conditions, the others under short days during stem growth, this being favourable to tuber formation in normal potato plants.

Stems growing from the buds showed abundant tuber formation in the leaf axils of cvs. Jaerla (early) and Bintje (mid early), especially under short-day conditions, but fewer tubers were formed in $\mathrm{cv}$. Alpha (late). This cultivar formed many thickened branches instead of tubers under short-day conditions. Under long days cvs. Jaerla and Bintje formed many above-ground tubers too, whereas one half of the cuttings of cv. Alpha did not form tubers at all.

When planted, above-ground tubers produced good yields and it may be concluded that the method described is potentially suitable for rapid multiplication purposes. Moreover, the method can easily be carried out by every seed potato grower at low cost.

\section{Introduction}

Generally, in the field, 10-25 seed tubers per plant are harvested depending on the cultivar. However, in glasshouses, more tubers per plant can be obtained by using stem cuttings. These cuttings produce 1-2 tubers each (Lauer, 1977; Murti et al., 1974). About 50 single-bud cuttings can be made from one plant, with 5 stems of 50-60 cm each. This means that 50-100 tubers can be obtained per plant. Although more tubers per plant were harvested, the number per cutting was low. 
Little has been published on above-ground tuber formation. In experiments of Ewing \& Wareing (1978) few tubers were formed in leaf axils in a certain clone, if all underground buds of the cuttings were removed. Stems affected by Rhizoctonia solani may form many above-ground tubers. In this case sugar transport to the underground parts is restrained by damage of the phloem tissue. Apparently a low underground sink activity stimulates above-ground tuber formation. In preliminary experiments tuber induction in leaf axils was studied in cv. Bintje. Many tubers occurred in these experiments and normal plants grew from these tubers (Marinus, unpublished). Because of this result an attempt was made to obtain similar effects in some cultivars producing few tubers per plant in the field.

For the production of healthy basic seed potatoes multiplication 'in vitro' is important in the Netherlands (Marinus, 1985). However, this method is mainly used for the rapid multiplication of protected cultivars. These are cultivars for which the breeders receive royalties from the growers. The aim of the present study was to find an alternative method of rapid multiplication for the other current cultivars (about 75).

\section{Materials and methods}

\section{Cultivars and growth of mother plants}

The multiplication of healthy basic seed in normal seed potato growing starts with only few plants. For cultivars producing a low number of tubers per plant in particular, it is important to improve the multiplication rate. For this reason cvs. Jaerla and Alpha were studied. Jaerla is an early cultivar, Alpha a late one. Because of some experience with cv. Bintje (mid-early and producing normally many tubers), this cultivar was also included in the experiment.

To obtain vigorously growing mother plants with long internodes 25 tubers were planted in a tray $(90 \mathrm{~cm} \times 70 \mathrm{~cm} \times 40 \mathrm{~cm})$ filled with a loose, fertile potting compost. The seed tubers of cv. Alpha were planted two weeks before the other cultivars, which emerge earlier and grow more rapidly (27 March and 10 April, respectively). Natural daylength was elongated to 18 hours by electric bulbs (one bulb of $15 \mathrm{~W}$ per tray, $50 \mathrm{~cm}$ above the plants). Throughout the whole experiment the temperature in the glasshouse was $18^{\circ} \mathrm{C}$.

\section{Cutting and rooting of the cuttings}

On 2 May stems of the mother plants were cut into single bud pieces with the leaves uppermost, and the largest part of each leaf was removed. The internodes were as long as possible with a maximum length of $6 \mathrm{~cm}$.

The cuttings were planted in trays $(80 \times 80 \times 18 \mathrm{~cm})$ filled with a mixture of equal volume parts of sand and peat. Cuttings were planted for rooting at 200 per tray and no hormones or fertilizers were used. To prevent drying out, the cuttings were covered with a transparent plastic sheet and a white cheese cloth was laid on this sheet on sunny days. To prevent rotting of the cuttings, the sheet was turned upside down every day. 


\section{Transplanting of the cuttings}

After rooting 30 cuttings were transplanted on 21 May into each deep tray (at 45 per $\mathrm{m}^{2}$ ) in the previously mentioned mixture of sand and peat ( 2 replicates). The cuttings were planted with the bases of the leaves (buds) some centimeters above the soil surface to prevent stolons growing into the soil.

In $\mathrm{cv}$. Bint je many cuttings were unrooted probably caused by a temporary lack of water. Therefore, unrooted cuttings also had to be planted in one replicate to obtain 30 cuttings per tray. As fertilizer, ammonium nitrate limestone ( $\left.20 \mathrm{~g} / \mathrm{m}^{2}\right)$. superphosphate $\left(\mathrm{P}_{2} \mathrm{O}_{5} 50 \mathrm{~g} / \mathrm{m}^{2}\right)$, potassium sulphate $\left(\mathrm{K}_{2} \mathrm{O} 30 \mathrm{~g} / \mathrm{m}^{2}\right)$ and kieserite $\left(\mathrm{MgO} 20 \mathrm{~g} / \mathrm{m}^{2}\right)$ were added.

\section{Treatments}

The stems growing from the axillary buds grew up under natural daylight (LD = long day). After one week one half of the cuttings was covered daily with a lightproof towel for 15 hours ( $\mathrm{SD}=9$ hours daylength) until stem growth had finished (from 29 May until 5 July) to promote tuberization. After this period these plants were re-exposed to LD conditions until harvest (22 and 23 August).

\section{Results}

\section{Rooting of cuttings}

All the cuttings of cvs. Jaerla and Alpha were rooted at transplanting, but rather poorly. In cv. Bintje about $2 / 3$ of the cuttings were unrooted in one replicate. Some of these died, influencing the number of tubers per $\mathrm{m}^{2}$ unfavourably.

\section{Growth and development of tubers}

The data are related to all the planted cuttings, including the dead ones in cv. Bintje (8 under SD, 3 under LD). Above-ground and underground tubers will be indicated by 'green' and 'white', respectively. In the green tubers brown spots occurred, possibly caused by lack of calcium. Percentages of these tubers varied between treatments and between cultivars. These percentages were: Jaerla 4 (SD) and 5 (LD), Bintje 1 (SD and LD) and Alpha 10 (SD only).

In Table 1 numbers refer to tubers $>13 \mathrm{~mm}$ (without thickened branches), because these tubers can be effectively stored and planted.

The number of tubers showed distinct differences between treatments and between cultivars within each treatment. In the SD treatment most tubers were formed (Fig. 1, Table 1). Especially cvs. Jaerla and Bintje showed abundant formation of green tubers and only few white ones. The proportion of white tubers was higher under LD than under SD, indicating that under LD more stolons grew into the soil. Compared with the replicate in which all cuttings had rooted, the replicate with $2 / 3$ of the cuttings unrooted at transplanting the number of tubers was $35 \%$ and $20 \%$ lower under SD and LD, respectively (cv. Bintje).

In cv. Alpha more white tubers were formed under SD than under LD. This cultivar also produced thickened branches in the leaf axils instead of tubers under SD, and under LD many plants did not tuberize at all. 
Table 1. Number of tubers ( $>13 \mathrm{~mm}$ ) per $\mathrm{m}^{2}$ and per cutting under short-day (SD) and long-day (LD) conditions of cvs. Jaerla, Bintje and Alpha.

\begin{tabular}{llllll}
\hline Cultivar & Daylength & \multicolumn{2}{l}{ Per $\mathrm{m}^{2}$} & & Per cutting, \\
\cline { 3 - 6 } & & green & white & total & total \\
Jaerla & SD & 357 & 1 & 358 & 8.0 \\
& LD & 166 & 34 & 200 & 4.4 \\
Bintje & SD & 292 & 7 & 299 & 6.6 \\
& LD & 101 & 51 & 152 & 3.4 \\
Alpha & SD & 168 & 29 & 197 & 4.4 \\
& LD & 5 & 22 & 27 & 0.6 \\
\hline
\end{tabular}

\section{Variability}

Variability in total number of tubers per cutting is presented in Table 2. The number of tubers include the small ones $(5-13 \mathrm{~mm})$ and the thickened sprouts, the number of which was not counted per cutting.

In all cultivars most tubers per cutting were obtained under SD. In cv. Jaerla one third of the cuttings produced over 10 tubers, whereas in cv. Bintje incidentally more than 20 tubers were harvested per cutting.

Under LD with cv. Alpha one half of the cuttings did not tuberize, but many very thickened stem bases were observed below soil level. This phenomenon also
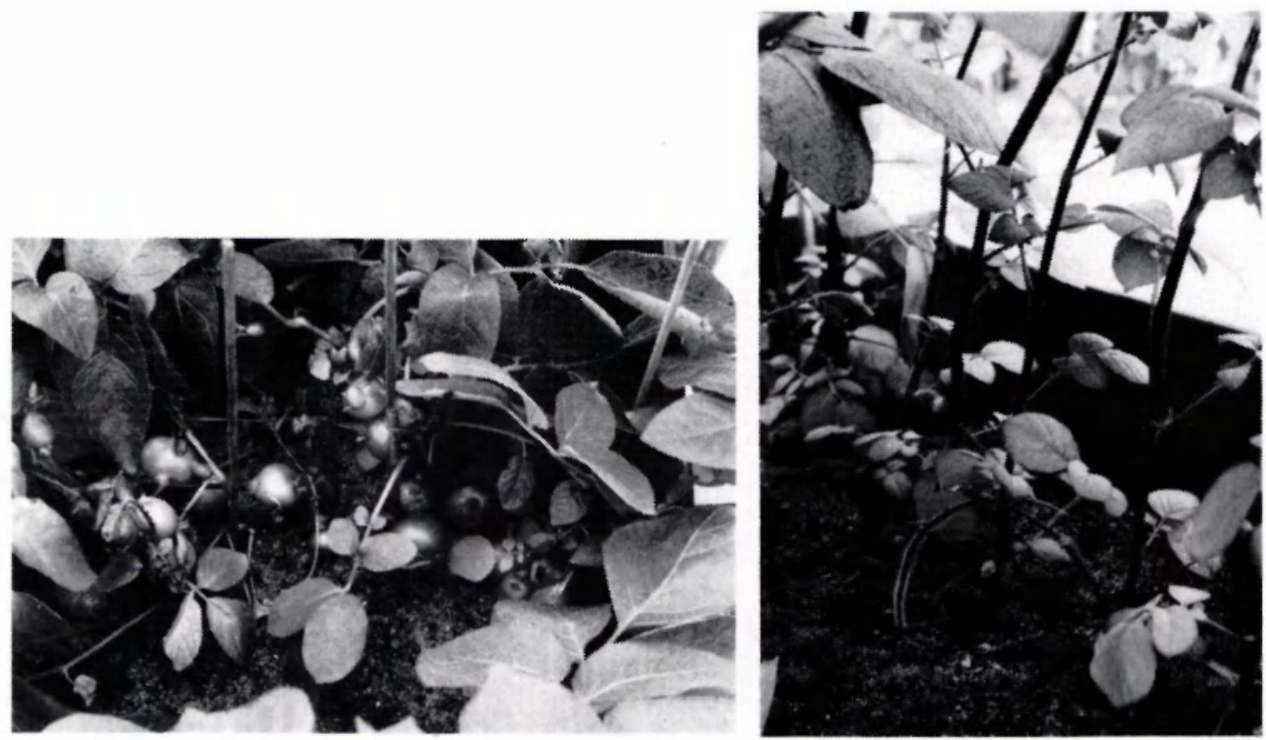

Fig. 1. Tubers (short day) and stolons (long day) in cv. Bintje, one week before harvest. 
Table 2. Frequency distribution of the number of cuttings with number of tubers indicated, under shortday (SD) and long-day (LD) conditions for cvs. Jaerla, Bintje and Alpha. All 60 cuttings are taken into account, including the dead ones.

\begin{tabular}{llrrrrr}
\hline \multirow{2}{*}{ Cultivar } & Daylength & \multicolumn{5}{l}{ Number of tubers per cutting } \\
\cline { 3 - 7 } & & 0 & $1-5$ & $6-10$ & $11-15$ & $>15$ \\
Jaerla & SD & 0 & 9 & 31 & 20 & 0 \\
& LD & 0 & 32 & 27 & 1 & 0 \\
Bintje & SD & 8 & 11 & 27 & 11 & 3 \\
& LD & 3 & 39 & 18 & 0 & 0 \\
Alpha & SD & 0 & 16 & 32 & 12 & 0 \\
& LD & 29 & 31 & 0 & 0 & 0 \\
\hline
\end{tabular}

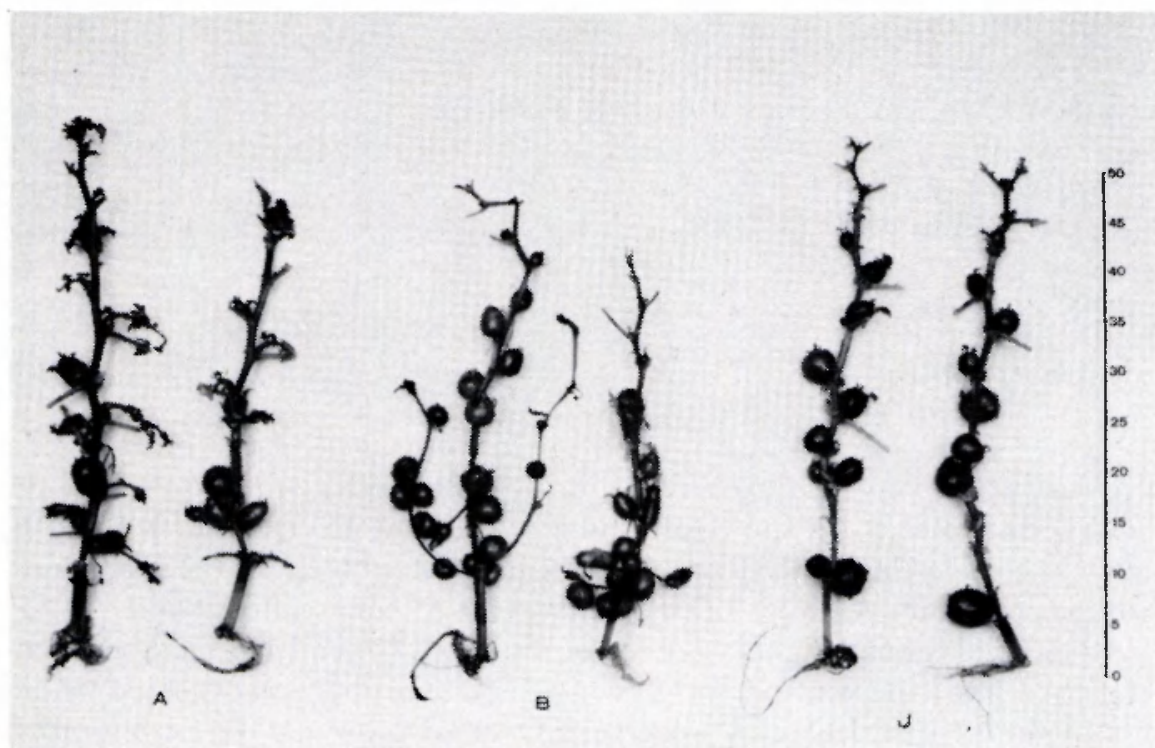

Fig. 2. Tubers in leaf axils under short day conditions in cvs. Alpha (A), Bintje (B) and Jaerla (J) at harvest.

occurred under SD and in the other cultivars with both treatments, but was less pronounced.

Fig. 2 demonstrates differences in tuber formation between cultivars under SD. $\mathrm{Cv}$. Alpha differs from the other cultivars by the formation of branches in the leaf axils. 
Table 3. Fresh weight $\left(\mathrm{kg} / \mathrm{m}^{2}\right)$ and grading of tubers under short-day (SD) and long-day (LD) conditions of cvs. Jaerla, Bintje and Alpha.

\begin{tabular}{|c|c|c|c|c|c|c|}
\hline \multirow[t]{2}{*}{ Cultivar } & \multirow[t]{2}{*}{ Daylength } & \multirow{2}{*}{$\begin{array}{l}\text { 'Type' of } \\
\text { tubers }\end{array}$} & \multicolumn{4}{|c|}{ Fresh weight $\left(\mathrm{kg} / \mathrm{m}^{2}\right)$ in size class } \\
\hline & & & $5-13 \mathrm{~mm}$ & $13-35 \mathrm{~mm}$ & $>35 \mathrm{~mm}$ & total \\
\hline \multirow[t]{6}{*}{ Jaerla } & SD & green & 0.04 & 3.17 & 0.50 & 3.71 \\
\hline & & white & 0 & 0 & 0.03 & 0.03 \\
\hline & & total & 0.04 & 3.17 & 0.53 & 3.74 \\
\hline & LD & green & 0.03 & 1.71 & 0.15 & 1.89 \\
\hline & & white & 0 & 0.23 & 1.46 & 1.69 \\
\hline & & total & 0.03 & 1.94 & 1.61 & 3.58 \\
\hline \multirow[t]{6}{*}{ Bintje } & SD & green & 0.04 & 2.71 & 0.32 & 3.07 \\
\hline & & white & 0 & 0.02 & 0.51 & 0.53 \\
\hline & & total & 0.04 & 2.73 & 0.83 & 3.60 \\
\hline & LD & green & 0.02 & 0.92 & 0.14 & 1.08 \\
\hline & & white & 0 & 0.54 & 2.00 & 2.54 \\
\hline & & total & 0.02 & 1.46 & 2.14 & 3.62 \\
\hline \multirow[t]{6}{*}{ Alpha } & $\mathrm{SD}^{*}$ & green & 0.03 & 1.58 & 0.02 & 1.63 \\
\hline & & white & 0 & 0.71 & 0.89 & 1.60 \\
\hline & & total & 0.03 & 2.29 & 0.91 & 3.23 \\
\hline & LD & green & 0.01 & 0.01 & 0 & 0.02 \\
\hline & & white & 0 & 0.28 & 0.31 & 0.59 \\
\hline & & total & 0.01 & 0.29 & 0.31 & 0.61 \\
\hline
\end{tabular}

* Without thickened branches.

\section{Fresh weight tubers}

In cvs. Jaerla and Bintje the same total tuber weights were obtained with both treatments (Table 3). Under SD these were mainly determined by the $13-35 \mathrm{~mm}$ fraction of the green tubers, under LD by the large $(>35 \mathrm{~mm})$ white tubers.

In cv. Alpha total tuber weights were lower, under SD equally divided between the green $(13-35 \mathrm{~mm})$ and white tubers of which a great proportion occurred in the $13-35 \mathrm{~mm}$ fraction. Under LD total tuber weight was very low and the formation of green tubers was negligible. The proportion of white tubers in the fractions 13-35 $\mathrm{mm}$ and $>35 \mathrm{~mm}$ was the same.

When comparing the total weight of green and white tubers with their numbers (Table 1), the white tubers were larger than the green ones.

\section{Progeny}

To get an impression of the reproductive value of the above-ground tubers some of these tubers of $\mathrm{cv}$. Bintje were planted in a glasshouse at $18{ }^{\circ} \mathrm{C}$ and under $\mathrm{LD}$. Tubers of different sizes, obtained in 1984 , were stored at $4{ }^{\circ} \mathrm{C}$ in darkness, and in 1985 were planted in containers $(90 \mathrm{~cm} \times 70 \mathrm{~cm} \times 40 \mathrm{~cm})$ filled with white sand. 


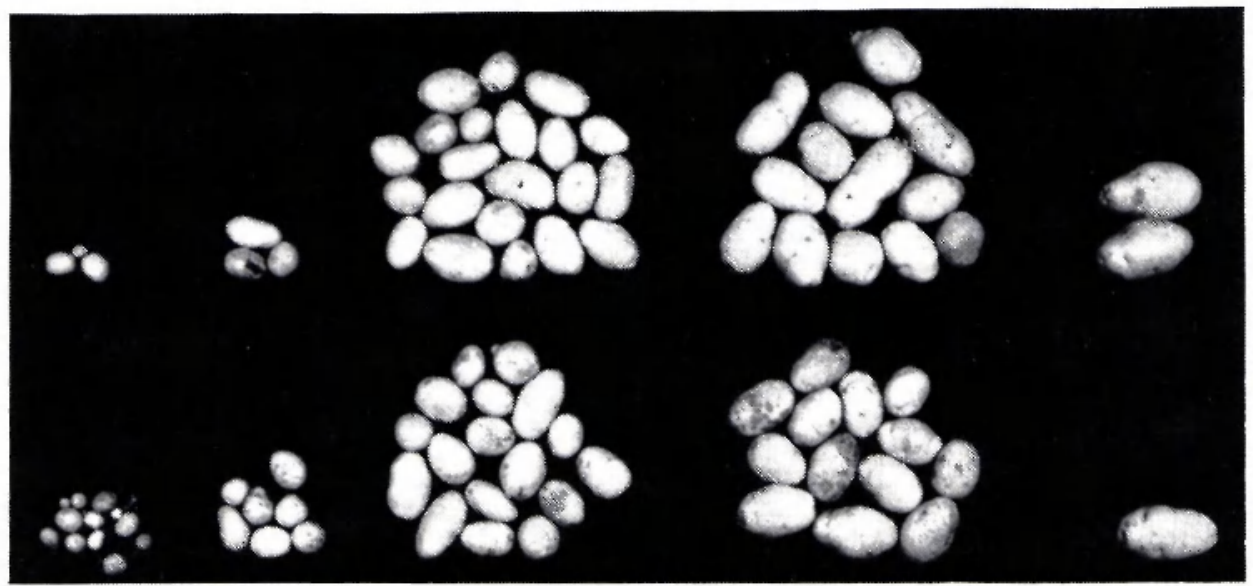

Fig. 3. Tubers of cv. Bintje in 1985 per 12 planted above-ground seed tubers $(10-15 \mathrm{~mm})$, obtained in 1984 under short day (below) and long day (above). Tuber grading (from left to right) 13-28, 28-35, 35$45,45-55$, and $>55 \mathrm{~mm}$.

Fertilizer was added at the same rate as before. From each treatment and each tuber size 12 tubers were planted in a tray. The tubers were small, namely $10-15 \mathrm{~mm}$, 15-20 $\mathrm{mm}$ and $20-25 \mathrm{~mm}$. The plants were harvested at complete senescence.

Even plants from tuber size $10-15 \mathrm{~mm}$ yielded well (Fig. 3). This means that even small tubers formed in leaf axils can be used for further multiplication, as long as storage can be survived. This was confirmed in a field experiment in 1986 in the progeny of the cultivars discussed.

\section{Discussion and conclusion}

In leaf axils of potato plants many tubers can be formed depending on variety. To promote above-ground tuber formation, underground tuber formation has to be prevented. This was done by planting single-bud stem cuttings with the leaf axils some centimetres above the soil surface. By covering the plants for 5 weeks around the longest day, total irradiance was markedly decreased in the SD treatments. Despite these unfavourable light conditions for tuber production, many more above-ground tubers were formed under SD than under LD. The formation of thickened branches instead of tubers by cv. Alpha cannot be explained yet. It may be a characteristic of late cultivars.

Above-ground tubers are not in contact with the soil and are therefore probably free of Rhizoctonia, for example, which is an advantage.

Our alternative method of rapid multiplication of healthy basic seed potatoes can easily be carried out by seed potato growers at low cost. As an example, cv. Jaerla produces in traditional seed potato growing 8-10 tubers per plant. With stems of 50$60 \mathrm{~cm}$ length and 5 stems per plant about 50 cuttings can be made. Production of 10 tubers per cutting (20 had 11-15 tubers) gives 500 tubers from one mother plant. 


\section{J. MARINUS}

For rapid multiplication the number of cuttings per mother plant can be increased by making cuttings repeatedly from both mother plants and growing cuttings. Cole \& Wright (1976) and Goodwin (1981) obtained 625 and 1500 cuttings, respectively, from one mother plant. The average number of tubers per cutting can probably be increased in the cultivars studied, for example at wider spacing like in underground tuber formation (Marinus, 1985). Other possibilities may be found in methods that increase the number of leaf axils (e.g. two-shoot plants).

It should be emphasized that, especially for rapid multiplication of basic seed, the mother plants have to be healthy in all respects.

\section{References}

Cole, E. F. \& N. S. Wright, 1967. Propagation of potato by stem cuttings. American Potato Journal 44: 301-304.

Ewing, E. E. \& P. E. Wareing, 1978. Shoot, stolon and tuber formation on potato (Solanum tuberosum L.) cuttings in response to photoperiod. Plant Physiology 61: 348-353.

Goodwin, P. B., 1981. Rapid propagation of potato by single node cuttings. Field Crop Research 4: 165173.

Lauer, F. I., 1977. Tubers from leaf bud cuttings: a tool for potato seed certification and breeding program. American Potato Journal 54: 457-464.

Marinus, J., 1985. Description of methods and experience of 'in vitro' multiplication of potatoes in the Netherlands. Netherlands Journal of Agicultural Science 33: 322-324.

Murti, G. S. R., S. N. Saha \& V. N. Banerjee, 1974. Sensitivity of growth and tuberization of stem cuttings of Solanum tuberosum L. to night temperatures. Indian Journal of Experimental Biology 12: 293-294. 